\title{
Semeadura direta com diferentes mecanismos sulcadores: alterações em propriedades de um Latossolo Bruno e produtividade das culturas
}

\author{
Direct seeding with different furrow openers: changes in properties of a South Brazilian latosol \\ (oxisol) and crop yields
}

\section{Franciani Rodrigues da Silva ${ }^{1 *}$, Jackson Adriano Albuquerque ${ }^{2}$, Diego Bortolini ${ }^{2}$, André da Costa ${ }^{3} \&$ Sandra Mara Vieira Fontoura ${ }^{4}$}

\author{
${ }^{1}$ Empresa de Pesquisa Agropecuária e Extensão Rural de Santa Catarina, Florianópolis, SC, Brasil. *Autor para correspondência: \\ francianiagro@yahoo.com.br. \\ 2 Universidade do Estado de Santa Catarina, Lages, SC, Brasil. \\ ${ }^{3}$ Instituto Federal Catarinense, Rio do Sul, SC, Brasil. \\ ${ }^{4}$ Fundação Agrária de Pesquisa Agropecuária, Guarapuava, PR, Brasil.
}

Submissão: 25/04/2017 | Aceite: 13/06/2018

\begin{abstract}
RESUMO
Os mecanismos das semeadoras para cortar os resíduos vegetais, mobilizar a camada superficial do solo e depositar as sementes nos sulcos modificam os atributos do solo e interferem no crescimento das culturas. Portanto, comparar os efeitos destes mecanismos é necessário. Este estudo objetivou avaliar o efeito de diferentes mecanismos sulcadores de semeadora-adubadoras, e da escarificação, sobre atributos de um Latossolo Bruno alumínico típico, e na produtividade de culturas. Os tratamentos avaliados foram: sulcadores tipo disco duplo (DD); sulcadores tipo guilhotina (GUI); sulcadores tipo facão (FA); e escarificação seguido de disco duplo (ESC+DD). Amostras de solo foram coletadas nas camadas de 0-10, 10-20 e 20-40 cm para avaliar atributos físicos (densidade, porosidade total, macro e microporosidade), químicos ( $\mathrm{pH}, \mathrm{Ca}, \mathrm{Mg}, \mathrm{K}$ e P) e conteúdo de carbono orgânico. Avaliou-se a matéria seca da parte aérea da soja e a produtividade das culturas em três safras distintas. Foi testada a normalidade dos dados, e realizada a análise da variância (teste $F$ a $p<0,05$ ), e apresentando significância as médias foram comparadas pelo teste de Tukey a $5 \%$. Os atributos de solo foram analisados para cada camada separadamente. Após quatro anos observou-se que a densidade do solo ainda é afetada pela escarificação, que a reduziu. A utilização sucessiva de DD no inverno para a implantação das culturas provocou homogeneização do solo, não diferindo as demais propriedades físicas e químicas. De maneira geral a produtividade de grãos e massa seca foram superiores no tratamento onde houve escarificação, utilização do disco duplo no verão e utilização do facão, em comparação a guilhotina.
\end{abstract}

PALAVRAS-CHAVE: implementos agrícolas, semeadora, física do solo.

\begin{abstract}
The mechanisms of seeding machines to cut the mulch, mobilize the topsoil and deposit the seeds in the furrows modify soil properties and interfere in crop growth. This study sought to evaluate the effects of furrow openers and scarification on the attributes of a South Brazilian latosol (Bruno - oxisol) and crop yields. The treatments were: double disc furrow opener (DD); shovel type furrow opener (S); shoe type furrow opener (SH); and scarification followed by double disc furrow opener (SC+DD). Samples were collected at 0-10, 1020 and $20-40 \mathrm{~cm}$ and evaluated for soil physical (bulk density, total porosity, macro and microporosity), chemical $(\mathrm{pH}, \mathrm{Ca}, \mathrm{Mg}, \mathrm{K}$ and $\mathrm{P})$ and organic carbon content. The normality of data was tested, and the analysis of the variance was performed ( $F$ test, $p<0.05$ ), and the means was compared by Tukey's test $(p=0.05)$. Soil attributes were analyzed for each layer separately. After four years it was observed that the bulk density is still affected by scarification, which reduces it. The successive use of DD in the winter for the implantation of the crops caused the homogenization of the soil, although with no differences on the other physical and chemical properties. In general, grain yield and dry mass were higher in the treatment that used scarification and the double disc during the summer, and the shoe type when compared to shovel type.
\end{abstract}

KEYWORDS: agricultural implements, seeding machine, soil physics. 


\section{INTRODUÇÃO}

O aumento da densidade do solo juntamente com redução do volume de poros, principalmente de macroporos, pode causar compactação excessiva, e em áreas agrícolas está relacionada principalmente ao sistema de manejo do solo. No sistema de semeadura direta ocorre nas camadas mais superficiais do solo, principalmente devido ao tráfego das máquinas agrícolas, rearranjo natural das partículas do solo e ao preparo restrito à linha de semeadura. Sendo assim, para minimizar estes efeitos na camada superficial, alguns agricultores acabam escarificando o solo antes da semeadura (CAMARA \& KLEIN 2005, KLEIN et al. 2008).

Em sistema de semeadura direta os mecanismos sulcadores integrados a semeadora-adubadora rompem a camada superficial do solo no momento da semeadura. Vários são os tipos de mecanismos sulcadores integrados às semeadoras-adubadoras utilizadas em sistema de semeadura direta, com desempenhos que variam com a textura e estrutura do solo e a quantidade de resíduos vegetais na superfície do solo. Dentre os principais mecanismos estão o disco duplo, o facão e a guilhotina.

$\mathrm{O}$ sulcador tipo duplo disco abre sulcos em forma de $\mathrm{V}$ e pode compactar as paredes do sulco de deposição da semente, reduzindo o fluxo de água naquela região do solo (REIS et al. 2006). Já o tipo facão pode atuar até $15 \mathrm{~cm}$ de profundidade no solo, e segundo DRESCHER et al. (2011) reduz a compactação do solo, a exigência de tração e o custo da operação. KOAKOSKI et al. (2007) verificaram que este mecanismo aumenta a porosidade do solo em comparação ao uso de discos duplos. CAMARA \& KLEIN (2005) citam que o sulcador tipo guilhotina possui pequena resistência a tração, e consequentemente menor mobilização no sulco ocasionando menores alterações em propriedades do solo como a densidade e porosidade.

$O$ efeito dos mecanismos sulcadores nas culturas ocorre de forma direta no número de plântulas germinadas e desenvolvimento de raízes, e indireta na alteração da estrutura do solo no sulco mobilizado. Sob Latossolo Vermelho distroférrico de textura muito argilosa, TROGELLO et al. (2013), não encontraram influência significativa dos mecanismos sulcadores na produtividade do milho. Já para um Planossolo Háplico (textura franca com densidade mais elevada, $>1,3 \mathrm{Mg} \mathrm{m}^{-3}$, na camada 0 a $20 \mathrm{~cm}$ ), o uso do disco duplo diminuiu a produtividade de soja em comparação a disco ondulado e haste sulcadora (VIZZOTTO 2014).

Em casos onde há presença de camadas compactadas no solo sob sistema de semeadura direta a escarificação é eficiente para romper estas camadas, que comparado à aração, mobiliza e desagrega menos o solo e mantém maior quantidade de resíduos vegetais sobre a superfície (ROSA et al. 2008). Entretanto, COLLARES et al. (2008) observaram que o efeito da escarificação na densidade de um Latossolo Vermelho não foi observado após 40 dias do preparo. Já SEKI et al. (2015) observaram que os efeitos de redução na densidade do solo persistiram após a colheita da primeira cultura subsequente a escarificação, e que não houve diferenças significativas entre escarificação e uso de mecanismos sulcadores (haste e disco duplo), em Nitossolo Vermelho de textura argilosa.

Devido às características do sistema de semeadura direta, quanto à mobilização do solo, objetivou-se, com esse trabalho, avaliar o efeito de diferentes mecanismos sulcadores das semeadora-adubadoras e da escarificação, sobre atributos de um Latossolo Bruno alumínico típico e na produtividade de culturas.

\section{MATERIAL E MÉTODOS}

O trabalho foi realizado numa área experimental da Fundação Agrária de Pesquisa AgropecuáriaFAPA, localizada no distrito de Entre Rios, município de Guarapuava, PR, situado no terceiro planalto paranaense a $1.100 \mathrm{~m}$ de altitude. O clima da região, segundo a classificação de Köppen, é subtropical úmido sem estação seca e com ocorrência de geadas frequentes e severas. A precipitação pluvial e a temperatura média anual são $1.956 \mathrm{~mm}$ e $16,9^{\circ} \mathrm{C}$, respectivamente. O solo da área é um Latossolo Bruno alumínico típico (EMBRAPA 2013), de textura argilosa (Tabela 1), relevo suave ondulado e substrato basalto.

Tabela 1. Composição granulométrica e teor de carbono orgânico do Latossolo Bruno alumínico típico, avaliado antes da implantação do experimento (2005).

Table 1. Granulometric composition and organic carbon content of the Bruno latosol, evaluated before the start of the experiment (2005).

\begin{tabular}{|c|c|c|c|c|}
\hline Camada & Argila & Silte & Areia & $\mathrm{CO}$ \\
\hline $0-10$ & 427 & 521 & 52 & 41 \\
\hline $10-20$ & 532 & 423 & 45 & 55 \\
\hline $20-40$ & 595 & 361 & 44 & 52 \\
\hline
\end{tabular}

O experimento foi implantado na primavera de 2005, sendo essa área experimental cultivada há mais 
de 20 anos sob sistema de semeadura direta. Para a semeadura das culturas de verão foram utilizados diferentes tipos de sulcadores, constituindo os tratamentos: sulcadores tipo disco duplo (DD); sulcadores tipo guilhotina (GUI); sulcadores tipo facão (FA); e escarificação e disco duplo (ESC+DD). No tratamento ESC+DD foi realizada escarificação na implantação do experimento, anteriormente a semeadura da cultura de verão, sendo esta repetida sempre que fosse detectado que o solo estivesse compactado. Assim, foi empregada novamente a escarificação no tratamento ESC+DD em outubro de 2009 , quatro anos após a implantação do experimento e três meses antes da coleta das amostras de solo.

Para a implantação das culturas de inverno utilizou-se semeadora com DD em toda área experimental. O experimento seguiu um esquema de rotação de culturas: cevada e aveia (inverno de 2005, 2006 e 2007) antecedendo a cultura da soja (verão 2005/2006, 2006/2007, 2007/2008 e 2009/2010); e consórcio de nabo com ervilhaca (inverno 2008) antecedendo a cultura do milho (verão 2008/2009).

$\mathrm{O}$ delineamento experimental utilizado foi em blocos ao acaso com quatro repetições. As parcelas mediam $12 \mathrm{~m}$ de largura e $8 \mathrm{~m}$ de comprimento e todas as operações dos tratos culturais e colheita foram realizadas com implementos e máquinas de lavouras comerciais.

A produtividade da soja foi determinada nas safras 2005/2006 e 2006/2007 e do milho na safra 2008/2009, coletando-se $96 \mathrm{~m}^{2}$ de área da parcela para a soja, e $38,4 \mathrm{~m}^{2}$ para o milho, extrapolando a produtividade para $\mathrm{kg} \mathrm{ha}^{-1}$ ajustada a uma umidade de grãos de $13 \%$. Em janeiro de 2010 foram coletadas, em $1 \mathrm{~m}^{2}$ de área da parcela, plantas para a determinação da massa seca da parte aérea da soja, posteriormente seca em estufa com fluxo contínuo de ar à $65^{\circ} \mathrm{C}$, sendo extrapolado para $\mathrm{kg} \mathrm{ha}^{-1}$.

Em janeiro de 2010 foram coletadas amostras de solo nas camadas de 0-10, 10-20 e 20-40 cm para determinação dos atributos físicos e químicos do solo. Amostras com estrutura preservada foram coletadas em anéis metálicos com $2,5 \mathrm{~cm}$ de altura e $6,0 \mathrm{~cm}$ de diâmetro interno. Após a coleta, os anéis foram saturados e submetidos à tensão de $6 \mathrm{kPa}$ em mesa de tensão de areia, e após foram secas em estufa a $105^{\circ} \mathrm{C}$ para obtenção da densidade do solo pelo método do anel volumétrico. Foi calculada a porosidade total (PT), pela diferença de umidade entre o solo saturado e o solo seco; microporosidade pela diferença de umidade entre o solo na tensão de $6 \mathrm{kPa}$ e o solo seco; e macroporosidade através da diferença entre PT e microporosidade.

Amostras com estrutura alterada foram coletadas para determinar $\mathrm{pH}$ em água, teores de $\mathrm{Ca} \mathrm{e} \mathrm{Mg}$ trocáveis, $\mathrm{K}$ e $\mathrm{P}$ extraíveis, e carbono orgânico (TEDESCO et al. 1995). Além desses, foi determinada a estabilidade de agregados por agitação vertical úmida de subamostras compreendidas entre 4,76 e 8,00 mm de diâmetro (KEMPER \& CHEPIL 1965), sendo os resultados expressos pelo diâmetro médio geométrico (DMG).

Os atributos de solo foram analisados para cada camada separadamente, sendo realizado o teste de normalidade de Shapiro-Wilk. Os dados com distribuição diferente da normal foram normalizados para realizar a análise da variância (teste $F$ a $p<0,05$ ). Nos atributos que foram significativos suas médias foram comparadas pelo teste de Tukey a $5 \%$.

\section{RESULTADOS E DISCUSSÃO}

A densidade do solo na camada de $0-10 \mathrm{~cm}$ variou de $1,00 \mathrm{Mg} \mathrm{m}^{-3}$ no ESC+DD a $1,07 \mathrm{Mg} \mathrm{m}^{-3}$ no GUI (Tabela 2). A escarificação anterior a semeadura com uso do DD reduziu a densidade do solo em relação aos demais tratamentos, pois o revolvimento através destes mecanismos aumenta a porosidade do solo. Neste sentido CAMARA \& KLEIN (2005) também verificaram redução da densidade de um Latossolo Vermelho com o uso de escarificadores antes da semeadura em relação ao revolvimento apenas por guilhotina ou disco duplo. Segundo SECCO et al. (2009) a camada compreendida entre 8 e $15 \mathrm{~cm}$, é a camada que recebe a pressão dos rodados das máquinas agrícolas mantendo-se compactada pela ausência da mobilização do solo. Nas camadas de 10-20 e 20-40 cm não houve diferença significativa entre os tratamentos.

Em relação à porosidade total do solo, não houve diferenças entre os tratamentos nas camadas avaliadas (Tabela 2). Todavia, em trabalho realizado por KLEIN et al. (2008) num Latossolo Vermelho verificaram que a escarificação esporádica do solo aumentou a porosidade total.

A macroporosidade do solo não diferiu entre os tratamentos nas camadas avaliadas (Tabela 2). Apesar de não ter sido detectada diferença, é importante salientar que a macroporosidade está próxima de $0,10 \mathrm{~m}^{3}$ $\mathrm{m}^{-3}$, considerado o limite crítico, abaixo do qual ocorrem restrições para os fluxos de água e gases bem como para o crescimento radicular, como no caso do FA na camada de $20-40 \mathrm{~cm}$. CAMARA \& KLEIN (2005) também não verificaram diferenças na macroporosidade quando o solo foi escarificado em relação ao solo não escarificado. A ausência de diferenças entre os tratamentos em relação a macroporosidade do solo pode estar relacionado ao uso de DD na semeadura das culturas de inverno em todos os tratamentos.

A microporosidade do solo não foi alterada pela ação dos sulcadores até a profundidade de $40 \mathrm{~cm}$ 
(Tabela 2), efeito esse também relatado por DRESCHER et al. (2011) quando avaliaram o efeito de intervenções mecânicas para a descompactação de solos sob sistema de semeadura direta. A explicação para isso segundo os autores, é que a microporosidade do solo é fortemente influenciada pela granulometria e teor de carbono orgânico é pouco influenciada pelo tráfego de máquinas e implementos. O volume de microporos para todos os tratamentos é superior a $0,50 \mathrm{~m}^{3} \mathrm{~m}^{-3}$, e indica elevada capacidade do solo em reter água.

Alguns estudos salientam que o efeito do revolvimento tem duração variável. ROSA et al. (2008) ao analisarem o efeito da haste sulcadora de semeadoras, num Latossolo Vermelho de textura argilosa, observaram que na camada 0-0,10 m o efeito da escarificação do solo em aumentar a macroporosidade e reduzir a microporosidade e densidade do solo durou de dois a quatro anos. DRESCHER et al. (2011), em Latossolo Vermelho de textura argilosa, concluíram que o efeito do revolvimento do solo sob sistema de semeadura direta desaparece em poucos cultivos, no caso 2,5 anos após.

Tabela 2. Propriedades físicas com uso de escarificador e de diferentes mecanismos sulcadores de semeadoras em Latossolo Bruno Alumínico Típico.

Table 2. Physical properties with the use of scarification and different types of furrow openers on the Bruno latosol.

\begin{tabular}{|c|c|c|c|c|}
\hline Tratamentos & $\mathrm{DD}$ & $\mathrm{ESC}+\mathrm{DD}$ & FA & GUI \\
\hline Camada & & $\mathrm{DS}\left(\mathrm{Mg} \mathrm{m}^{-3}\right)(\mathrm{GC})$ & & \\
\hline $0-10 \mathrm{~cm}$ & $1,01(84 \%) a b$ & $1,00(83 \%) b$ & $1,05(87 \%) a b$ & $1,07(89 \%) \mathrm{a}$ \\
\hline $10-20 \mathrm{~cm}$ & $1,07(89 \%) a$ & $1,03(86 \%) \mathrm{a}$ & $1,03(86 \%) a$ & $1,06(88 \%) \mathrm{a}$ \\
\hline $20-40 \mathrm{~cm}$ & $1,01(84 \%) a$ & $\begin{array}{l}1,00(83 \%) \mathrm{a} \\
\text { PT }\left(\mathrm{m}^{3} \mathrm{~m}^{-3}\right)\end{array}$ & $1,05(87 \%) \mathrm{a}$ & $1,01(84 \%) \mathrm{a}$ \\
\hline $0-10 \mathrm{~cm}$ & $0,62 \mathrm{a}$ & $0,65 a$ & $0,62 \mathrm{a}$ & $0,62 \mathrm{a}$ \\
\hline $10-20 \mathrm{~cm}$ & $0,63 a$ & $0,62 \mathrm{a}$ & $0,63 a$ & $0,61 \mathrm{a}$ \\
\hline $20-40 \mathrm{~cm}$ & $0,64 \mathrm{a}$ & $\begin{array}{l}0,62 \mathrm{a} \\
\text { Macroporos }\left(\mathrm{m}^{3} \mathrm{~m}^{-3}\right)\end{array}$ & $0,60 \mathrm{a}$ & $0,62 \mathrm{a}$ \\
\hline $0-10 \mathrm{~cm}$ & $0,10 \mathrm{a}$ & $0,10 a$ & $0,09 a$ & $0,10 \mathrm{a}$ \\
\hline $10-20 \mathrm{~cm}$ & $0,11 \mathrm{a}$ & $0,09 a$ & $0,12 \mathrm{a}$ & $0,09 \mathrm{a}$ \\
\hline $20-40 \mathrm{~cm}$ & $0,11 \mathrm{a}$ & $\begin{array}{l}0,11 \mathrm{a} \\
\text { Microporos }\left(\mathrm{m}^{3} \mathrm{~m}^{-3}\right)\end{array}$ & $0,07 \mathrm{a}$ & $0,10 a$ \\
\hline $0-10 \mathrm{~cm}$ & $0,52 \mathrm{a}$ & $0,54 \mathrm{a}$ & $0,52 \mathrm{a}$ & $0,52 \mathrm{a}$ \\
\hline $10-20 \mathrm{~cm}$ & $0,52 \mathrm{a}$ & $0,53 \mathrm{a}$ & $0,51 \mathrm{a}$ & $0,52 \mathrm{a}$ \\
\hline $20-40 \mathrm{~cm}$ & $0,53 \mathrm{a}$ & $\begin{array}{l}0,51 \mathrm{a} \\
\mathrm{DMG}(\mathrm{cm})\end{array}$ & $0,53 \mathrm{a}$ & $0,53 \mathrm{a}$ \\
\hline $0-10 \mathrm{~cm}$ & $4,5 \mathrm{a}$ & $4,7 \mathrm{a}$ & $4,7 \mathrm{a}$ & $4,1 \mathrm{a}$ \\
\hline $10-20 \mathrm{~cm}$ & $3,7 \mathrm{a}$ & $3,2 \mathrm{a}$ & $3,9 a$ & $3,2 \mathrm{a}$ \\
\hline $20-40 \mathrm{~cm}$ & $2,5 \mathrm{a}$ & $2,0 \mathrm{~b}$ & $2,4 \mathrm{a}$ & $2,1 \mathrm{~b}$ \\
\hline
\end{tabular}

Tratamentos: DD: sulcadores tipo disco duplo; GUI: sulcadores tipo guilhotina; FA: sulcadores tipo facão; ESC+DD: escarificação + sulcador tipo disco duplo. Médias comparadas na linha pelo teste de Tukey $(p<0,05)$.

Em relação à estabilidade dos agregados, o DMG na camada de $0-10 \mathrm{~cm}$ variou de 4,1 a 4,7 $\mathrm{mm}$ e na camada de $10-20 \mathrm{~cm}$ variou de 3,2 a $3,9 \mathrm{~mm}$ (Tabela 2), no entanto, não foram observadas diferenças significativas entre os tratamentos. A alta estabilidade de agregados em todos os tratamentos pode estar relacionada ao elevado teor de matéria orgânica e de óxidos de ferro e alumínio presentes nesse Latossolo Bruno (SILVA et al. 2008), os quais atuam na estabilização dos agregados (VARADACHARI et al. 1997). Na camada de 20-40 cm o DMG foi maior no DD e no FA, diferindo significativamente dos demais tratamentos. Independente do tratamento houve diminuição do DMG com o aumento da profundidade, provavelmente relacionada à diminuição do teor da matéria orgânica e da ação das raízes das plantas nas camadas mais profundas do solo.

Diferentemente do observado nesse estudo, CALONEGO \& ROSOLEM (2008) verificaram, na camada de $5-10 \mathrm{~cm}$ de um Nitossolo Vermelho distroférrico de textura argilosa, que a escarificação do solo diminuiu a estabilidade de agregados e a porcentagem de agregados maiores que $2 \mathrm{~mm}$. Todavia, é importante considerar que cada solo responde de forma diferente à escarificação e que após essa prática a tendência é a acomodação das partículas do solo e, com o passar do tempo, a reconsolidação do mesmo (LIMA et al. 2006, KAISER 2010). Segundo MARCOLAN et al. (2007), o revolvimento do solo tende a homogeneizar a camada revolvida, tendendo assim, a ausência de diferenças dos atributos físicos do solo no tempo e entre profundidades. KAISER (2010) não detectou efeitos na estrutura em solo Argissolo Vermelho-Amarelo com textura franco arenosa, três meses após a mobilização do solo. Ou seja, nos solos arenosos o efeito da 
mobilização do solo é menos duradouro.

Os atributos químicos foram pouco afetados pelo uso de diferentes sulcadores e escarificador. Apesar de não haverem diferenças significativas ( $p>0,05)$, os maiores teores de $\mathrm{Ca}, \mathrm{Mg}, \mathrm{K}$ e $\mathrm{P}$ foram observados na camada superficial $(0-10 \mathrm{~cm})$ em todos os tratamentos. Todavia, o teor de CO foi menor na camada de 0-10 $\mathrm{cm}$, sobretudo nos tratamentos ESC+DD e FA. Tanto o ESC+DD como o FA possuem sistemas que promovem a remoção de parte dos resíduos da superfície, além de aumentarem a taxa de decomposição destes resíduos por incorporação e aumento do contato com a umidade e os microrganismos do solo.

Tabela 3. pH, teores de $\mathrm{Ca}, \mathrm{Mg}, \mathrm{K}, \mathrm{P}$ e carbono orgânico (CO) com uso de escarificador e de diferentes sulcadores em Latossolo Bruno Alumínico Típico.

Table 3. $\mathrm{pH}, \mathrm{Ca}, \mathrm{Mg}, \mathrm{K}, \mathrm{P}$ and organic carbon content with the use of scarification and different types of furrow openers on the Bruno latosol.

\begin{tabular}{|c|c|c|c|c|}
\hline Tratamentos & $\mathrm{DD}$ & $E S C+D D$ & FA & GUI \\
\hline Camada & & $\mathrm{pH}$ & & \\
\hline $0-10 \mathrm{~cm}$ & $5,6 \mathrm{a}$ & $4,9 \mathrm{a}$ & $5,3 a$ & $4,9 a$ \\
\hline $10-20 \mathrm{~cm}$ & $5,3 a$ & $5,0 \mathrm{a}$ & $5,3 a$ & $5,1 \mathrm{a}$ \\
\hline $20-40 \mathrm{~cm}$ & $5,2 \mathrm{a}$ & $\begin{array}{c}5,0 \mathrm{a} \\
\mathrm{Ca}\left(\mathrm{cmol}_{\mathrm{c} \mathrm{kg}}{ }^{-1}\right)\end{array}$ & $5,2 \mathrm{a}$ & $5,0 \mathrm{a}$ \\
\hline $0-10 \mathrm{~cm}$ & $4,2 \mathrm{a}$ & $4,9 a$ & $5,4 \mathrm{a}$ & $5,4 a$ \\
\hline $10-20 \mathrm{~cm}$ & $3,3 a$ & $3,6 \mathrm{a}$ & $4,4 \mathrm{a}$ & $4,5 \mathrm{a}$ \\
\hline $20-40 \mathrm{~cm}$ & $2,7 b$ & $\begin{array}{c}2,3 \mathrm{~b} \\
\mathrm{Mg}\left(\mathrm{cmol}_{\mathrm{c} \mathrm{kg}} \mathrm{kg}^{-1}\right)\end{array}$ & $2,8 \mathrm{~b}$ & $3,0 \mathrm{a}$ \\
\hline $0-10 \mathrm{~cm}$ & $3,6 \mathrm{a}$ & $3,1 \mathrm{a}$ & $3,2 \mathrm{a}$ & $3,4 a$ \\
\hline $10-20 \mathrm{~cm}$ & $2,5 \mathrm{a}$ & $1,9 \mathrm{~b}$ & $1,7 \mathrm{~b}$ & $1,9 \mathrm{~b}$ \\
\hline $20-40 \mathrm{~cm}$ & $1,2 a b$ & $\begin{array}{c}1,6 \mathrm{a} \\
\mathrm{K}\left(\mathrm{cmolc}_{\mathrm{ckg}}{ }^{-1}\right)\end{array}$ & $1,2 \mathrm{ab}$ & $1,1 \mathrm{~b}$ \\
\hline $0-10 \mathrm{~cm}$ & $0,21 \mathrm{a}$ & $0,23 a$ & $0,30 \mathrm{a}$ & $0,35 a$ \\
\hline $10-20 \mathrm{~cm}$ & $0,14 \mathrm{a}$ & $0,13 a$ & $0,31 \mathrm{a}$ & $0,19 b$ \\
\hline $20-40 \mathrm{~cm}$ & $0,22 \mathrm{a}$ & $\begin{array}{c}0,20 \mathrm{a} \\
\mathrm{P}\left(\mathrm{mg} \mathrm{kg}^{-1}\right)\end{array}$ & $0,21 \mathrm{a}$ & $0,18 b$ \\
\hline $0-10 \mathrm{~cm}$ & $10 \mathrm{a}$ & $10 a$ & $10 a$ & $7 a$ \\
\hline $10-20 \mathrm{~cm}$ & $5 \mathrm{ab}$ & $5 b$ & $6 \mathrm{a}$ & $2 b$ \\
\hline $20-40 \mathrm{~cm}$ & $2 b$ & $\begin{array}{c}4 \mathrm{~b} \\
\mathrm{CO}\left(\mathrm{g} \mathrm{kg}^{-1}\right)\end{array}$ & $6 a$ & $2 a$ \\
\hline $\begin{array}{l}0-10 \mathrm{~cm} \\
10-20 \mathrm{~cm} \\
20-40 \mathrm{~cm}\end{array}$ & $\begin{array}{l}42 \mathrm{a} \\
46 \mathrm{~b} \\
46 \mathrm{~b}\end{array}$ & $\begin{array}{l}40 a \\
58 a \\
55 a\end{array}$ & $\begin{array}{l}36 \mathrm{a} \\
59 \mathrm{a} \\
50 \mathrm{ab}\end{array}$ & $\begin{array}{l}46 a \\
56 a b \\
57 a\end{array}$ \\
\hline
\end{tabular}

Tratamentos: DD: sulcadores tipo disco duplo; ESC+DD: escarificação + sulcador tipo disco duplo; FA: sulcadores tipo facão; GUI: sulcadores tipo guilhotina. Médias comparadas na linha pelo teste de Tukey $(p<0,05)$.

Os teores de Ca e Mg estão acima dos recomendados pela CQFS-RS/SC (2004). Conforme a CQFS$\mathrm{RS} / \mathrm{SC}$ (2004) o teor de $\mathrm{K}$ deve estar acima de $0,15 \mathrm{cmolc} \mathrm{kg}^{-1}$, considerando que este solo tem CTC de 5,0 a $15 \mathrm{cmol}_{\mathrm{c}} \mathrm{kg}^{-1}$, o que foi observado em praticamente todos os tratamentos, com exceção da camada de 10-20 $\mathrm{cm}$ no DD e ESC+DD. Na primeira camada $(0-10 \mathrm{~cm})$ os teores de $P$ estão acima do considerado ideal em todos os tratamentos, porém em profundidade os teores passaram para médios a muito baixo (CQFS-RS/SC 2004).

A matéria seca da parte aérea da soja não diferiu entre os tratamentos $D$. Este fato deve-se principalmente à ausência de restrição química e física do solo. O uso sucessivo de sulcador tipo DD no inverno para a implantação das culturas mobiliza a camada superficial do solo impedindo a compactação nesta camada. Além disso, a correção e a adubação realizada com frequência nessa área mantêm os nutrientes acima do nível considerado crítico pela CQFS-RS/SC (2004).

A produtividade da soja foi maior no tratamento ESC+DD e FA em 2005/2006 (Figura 1A), e maior no FA, DD e GUI em 2006/2007 (Figura 1B). Para a cultura do milho o sulcador tipo GUI teve menor produtividade em relação ao tratamento ESC+DD (Figura 1C). SECCO et al. (2009) observaram maior produtividade de milho e trigo em Latossolos do Rio Grande do Sul após o uso de escarificadores. Por outro lado, CAMARA \& KLEIN (2005) verificaram que a produtividade da soja foi afetada positivamente após a utilização do sulcador tipo guilhotina num Latossolo Vermelho.

A alternância das maiores produtividades entre os diferentes tratamentos, anos agrícolas e culturas pode estar relacionado à dependência da produtividade das culturas à diversos fatores, como atributos físicos, químicos e biológicos do solo, além do manejo dado à cultura e das condições meteorológicas de cada safra. Segundo DRESCHER et al. (2011), a existência de condições meteorológicas favoráveis, principalmente a 
ocorrência de precipitações adequadas durante a condução das culturas, proporcionam maior umidade ao solo, podendo assim, beneficiar o desenvolvimento da cultura, amenizando as perdas de produtividade que poderiam ocorrer em decorrência da presença de camadas compactadas em subsuperfície.

Neste mesmo solo SILVA et al. (2014) verificaram que a cultura da soja teve crescimento normal da parte aérea até o grau de compactação de $93 \%$ e se desenvolveu menos quando o solo estava com GC acima de $93 \%$, comparativamente a este observa-se que a densidade do solo no presente estudo não atingiu este grau de compactação em nenhum dos tratamentos (Tabela 2) e, portanto, não foi observada restrição física que pudesse reduzir a produtividade das culturas nas condições e solo estudados.
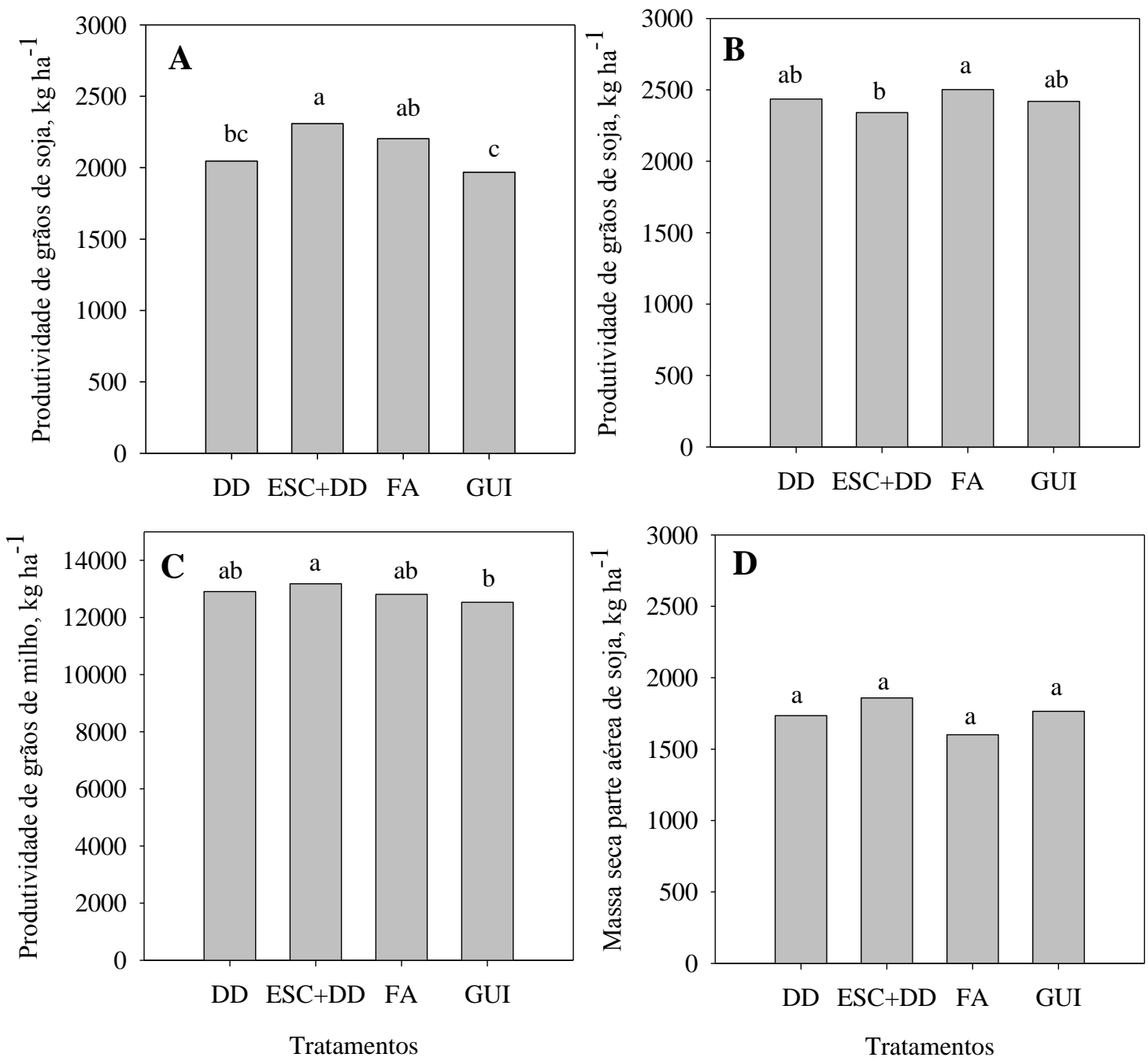

Figura 1. Produtividade de grãos da soja no ano agrícola de 2005/2006 (A) e 2006/2007 (B) e do milho no ano agrícola de 2008/2009 (C) e massa seca da parte aérea da soja, safra 2009/2010 (D) com uso de escarificador e de diferentes sulcadores. Médias comparadas pelo teste de Tukey $(p<0,05)$.

Figure 1. Soybean grain yield for crop years 2005/2006 (A) and 2006/2007 (B), and maize during the growing season 2008/2009 (C) and dry mass of the soybean shoot, 2009/2010 (D) with the use of scarification and different types of furrow openers on the Bruno latosol. Means compared by Tukey's test $(p<0.05)$.

\section{CONCLUSÃO}

O uso sucessivo do sulcador tipo disco duplo da semeadora no inverno para a implantação das culturas provocou homogeneização das propriedades físicas e químicas da área nas camadas avaliadas.

A ausência de restrição física e química do solo nos diferentes tratamentos não reduziu consideravelmente a produtividade das culturas nos diferentes anos.

\section{AGRADECIMENTOS}

Agradecimento a FAPA (Fundação Agrária de Pesquisa Agropecuária) pelo apoio experimental para a realização do experimento. 


\section{REFERÊNCIAS}

CALONEGO JC \& ROSOLEM CA. 2008. Estabilidade de agregados do solo após manejo com rotações de culturas e escarificação. Revista Brasileira de Ciência do Solo 32: 1399-1407.

CAMARA RK \& KLEIN VA. 2005. Propriedades físico-hídricas do solo sob plantio direto escarificado e rendimento da soja. Ciência Rural 35: 813-819.

CQFS- RS/SC. 2004. Comissão de Química e Fertilidade do Solo. Manual de adubação e de calagem para os estados do Rio Grande do Sul e de Santa Catarina. 10.ed. Porto Alegre: Sociedade Brasileira de Ciência do Solo. 400p.

COLLARES GL et al. 2008. Compactação de um Latossolo induzida pelo tráfego de máquinas e sua relação com o crescimento e produtividade de feijão e trigo. Revista Brasileira de Ciência do Solo 32: 933-942.

DRESCHER MS et al. 2011. Persistência do efeito de intervenções mecânicas para a descompactação de solos sob plantio direto. Revista Brasileira de Ciência do Solo 35: 1713-1722.

EMBRAPA. 2013. Sistema Brasileiro de Classificação de Solos. 3.ed. Brasília: EMBRAPA. 353p.

GENRO JUNIOR AS et al. 2004. Variabilidade temporal da resistência à penetração de um Latossolo argiloso sob semeadura direta com rotação de culturas. Revista Brasileira de Ciência do Solo 28: 477-484.

KAISER DR. 2010. Estrutura e água em Argissolo sob distintos preparos na cultura do milho. Tese (Doutorado em Ciência do Solo). Santa Maria: UFSM. 146p.

KEMPER WD \& CHEPIL WS 1965. Size distribution of aggregates. In: BLACK CA et al. (Eds). Methods of soil analysis Physical and mineralogical properties, including statistics of measurement and sampling. Part 1. Madison: American Society of Agronomy. p. 499-510.

KLEIN VA et al. 2008. Porosidade de aeração de um Latossolo Vermelho e rendimento de trigo em plantio direto escarificado. Ciência Rural 38: 365-371.

KOAKOSKI A et al. 2007. Desempenho de semeadora-adubadora utilizando-se dois mecanismos rompedores e três pressões da roda compactadora. Pesquisa Agropecuária Brasileira 42: 725-731.

LIMA CLR et al. 2006. Qualidade físico-hídrica e rendimento de soja (Glycine max L.) e feijão (Phaseolus vulgaris L.) de um Argissolo Vermelho distrófico sob diferentes sistemas de manejo. Ciência Rural 36: 1172-1178.

MARCOLAN AL et al. 2007. Recuperação de atributos físicos de um Argissolo em função do seu revolvimento e do tempo de semeadura direta. Revista Brasileira de Ciência do Solo 31: 571-579.

REIS EF et al. 2006. Densidade do solo no ambiente solo-semente e velocidade de emergência em sistema de semeadura de milho. Revista Brasileira de Ciência do Solo 30: 777-786.

ROSA DP et al. 2008. Relação entre solo e haste sulcadora de semeadora em Latossolo escarificado em diferentes épocas. Pesquisa Agropecuária Brasileira 43: 395-400.

SECCO D et al. 2009. Atributos físicos e rendimento de grãos de trigo, soja e milho em dois Latossolos compactados e escarificados. Ciência Rural 39: 58-64.

SEKI AS et al. 2015. Efeitos de práticas de descompactação do solo em área sob sistema plantio direto. Revista de Ciência Agronômica 46: 460-468.

SILVA FR et al. 2014. Crescimento inicial da cultura da soja em Latossolo Bruno com diferentes graus de compactação. Revista Brasileira de Ciência do Solo 38: 1731-1739.

SILVA V et al. 2008. Variáveis de acidez em função da mineralogia da fração argila do solo. Revista Brasileira de Ciência do Solo 32: 551-559.

TEDESCO MJ et al. 1995. Análises de solos, plantas e outros materiais. 2.ed. Porto Alegre: UFRGS. 174p.

TROGELLO E et al. 2013. Manejos de cobertura, mecanismos sulcadores e velocidades de operação sobre a semeadura direta da cultura do milho. Bragantia 72: 101-109.

VARADACHARI C et al. 1997. Complexation of humic substances with oxides of iron and aluminum. Soil Science 162: 2834.

VIZZOTTO VR. 2014. Desempenho de mecanismos sulcadores de semeadora-adubadora sobre os atributos físicos do solo em várzea no comportamento da cultura da soja (Glycine max L). Tese (Doutorado em Engenharia Agrícola). Santa Maria: UFSM. 78p. 